\title{
Algunas reflexiones sobre la novedad del recurso de casación en el orden jurisdiccional de lo contencioso-administrativo
}

\author{
Luciano Parejo Alfonso
}

Catedrático de Derecho Administrativo

Universidad Carlos III de Madrid

\begin{abstract}
SUMARIO: I. INTRODUGCIÓN. II. SOBRE EL REFORZAMIENTO DEL REGURSOS DE GASAGIÓN Y LA INTENSIFICACIÓN DE LA PROTEGGIÓN DE LOS GIUDADANOS. 1. Consideraciones Generales. 2. Balance posible de la reforma. III. CONCLUSIONES.
\end{abstract}

RESUMEN: El presente estudio aborda el nuevo sistema de casación en el orden contencioso-administrativo operado por la Ley Orgánica 7/2015 de 21 de julio criticando sus deficiencias técnicas. La introducción de la casación en el orden jurisdiccional contencioso-administrativo ha ido acompañada del abandono de la universalidad de la apelación, es decir, de la construcción del control prescrito por el artículo 106.1 CE sobre el principio de la doble instancia más que nomofiláctico, el recurso de casación actual se ofrece, pues, como nomotético. La casación se aparta, así, de lo nomofiláctico para convertirse en mecanismo depurador del control judicial cumplido en asuntos en los que esté afectado gran número de situaciones, tengan trascendencia social o esté en juego la integridad de los intereses generales. Hubiera sido preferible la remodelación del sistema sobre la base de la doble instancia (la universalidad de la apelación o apelación universal, pero restringida).Y la articulación de la casación bien -en línea de continuación con el proceso de "normalización" de lo contencioso-administrativo- sobre la lógica mucho más simple y clara de la casación civil.

PALABRAS CLAVE: Casación en el orden contencioso-administrativo. Análisis crítico, doble instancia apelación universal, casación civil.

ABSTRACT: The present study addresses the new system of cassation in the contentious-administrative order operated by the Organic Law 7/2015 of July 21 criticizing its technical deficiencies. The introduction of the cassation in the jurisdictional contentious-administrative order has been accompanied by the abandonment of the universality of the appeal, that is, the construction of the control prescribed 
by Article 106.1 Spanish Constitution on the principle of the double instance. More than nomofilactic, the current appeal is therefore offered as nomothetic. From the nomophylactic to become a debugging mechanism of judicial control fulfilled in matters in which a large number of situations are affected, have social transcendence or the integrity of the general interests is at stake. It would have been preferable to remodel the system on the basis of the double instance (the universality of the appeal or universal appeal, but restricted). And the articulation of the cassation -in continuation line with the process of "normalization" of the contentious-administrativeon the much simpler and clearer logic of the civil Cassation

KEY WORDS: Cassation judicial review of admnistrative Action. Critical analysis, double instance universal appeal, Civil Cassation.

\section{INTRODUGCIÓN}

La amplitud de la vacatio legis de la nueva regulación, en 2015, del recurso de casación dice por si sola de la trascendencia de ésta ${ }^{1}$, que ha sido objeto ya, en sus diversos aspectos, de análisis doctrinales ${ }^{2}$. Esa misma trascendencia impone, sin abundar por ello ahora en tales análisis, reflexionar sobre el significado y alcance

1 De "giro copernicano" y "vuelco a la anterior situación" habla RUIZ LÓPEZ, A. M. "El nuevo recurso de casación contencioso-administrativo: primeras resoluciones, balance y perspectivas, RAP núm. 204, septiembre-diciembre (2017), pp. 169 y 170.

2 Entre los más recientes, los tempranos de SANTAMARÍA PASTOR, J. A. "Una primera aproximación al nuevo sistema casacional", RAP núm. 198, septiembre-diciembre 2015; LOZANO CUTANDA, B. "La reforma del recurso de casación contencioso-administrativo por la Ley orgánica 7/2015: análisis de sus novedades", Actualidad administrativa, núm. 11, 2015; PÉREZ ALONSO, J. "El nuevo sistema de casación en el orden contencioso-administrativo operado por la Ley Orgánica 7/2015 de 21 de julio: con la vista puesta en el certiorari estadounidense", Diario La Ley núm. 8622, 2015; CÓRDOBA CASTROVERDE, D. "El nuevo recurso de casación contencioso-administrativo", Revista de furisprudencia, Lefebvre-El Derecho, 1 de octubre de 2015; así como los de FERNÁNDEZ GARCÍA, J. F. "Lo nuevo y lo viejo del recurso de casación contencioso-administrativo: admisibilidad y motivos de impugnación", RAP núm. 202, enero-abril 2017, pp. 337-379; RUIZ LÓPEZ, M. A. (2017: 165-202); y QUINTANA CARRETERO, J. P. El recurso de casación autonómica del orden contencioso-administrativo: su asimétrica e insatisfactoria configuración, Lefebvre- El Derecho, El Derecho.com, 2017/510088.

A los anteriores deben añadirse, RUIZ LÓPEZ, M. A. La reforma del recurso de casación contencioso-administrativo, Ed. Tirant lo Blanch, Valencia 2016; CAZORLA PRIETO, L. Mª y CANCIO FERNÁNDEZ, R. C. (coords.), Estudios sobre el nuevo recurso de casación contencioso-administrativo, Ed. Aranzadi, 2017; HUELIN MARTÍNEZ DE VELASCO, J. "La nueva casación contencioso-administrativa (primeros pasos)", Revista General de Derecho Constitucional, núm. 24; NAVARRO VEGA, M․ B. (coord.), Recientes reformas de la Ley de la furisdicción Contenciosa-Administrativa, el recurso de casación y la ejecución de las sentencias de derribo, Ed. Tirant lo Blanch, 2017; VELASCO CABALLERO, F. "Poderes del Tribunal Supremo en la casación contencioso-administrativa", REDA núm. 182, pp. 135-180, y DELGADO PIQUERAS, F. "Luces y sombras de la reforma del recurso de casación en la jurisdicción contencioso-administrativa” (pp. 745-766) y QUINTANA LÓPEZ, T. "Algunos aspectos de la nueva regulación sobre el recurso de casación frente a sentencias en el orden contencioso-administrativo. El trámite de admisión” (pp. 767-794), en PAREJO ALFONSO, L. y 
de la reforma, poniendo el acento en su dimensión sustantiva antes que en la procedimental. Aunque quizás sea aún muy pronto para efectuar una fundada valoración de conjunto de la misma, no puede dejar de resaltarse que su acelerada tramitación parlamentaria ni parece compatible con los "principios de buena regulación" ahora tan en boga y positivizados en el artículo 129 LPAC, ni proporciona precisamente una sólida base para la aseveración de la calidad de la reforma legal. Por lo demás, algunos detalles de su texto aportan botones de muestra de la falta de una mayor depuración técnica del texto aprobado; en particular: i) la alusión genérica a los Juzgados de lo Contencioso-Administrativo en el inciso inicial del artículo 86.1 LJCA que, a tenor de la literalidad del artículo 6, a) y b), no es capaz de comprender la totalidad de los órganos judiciales unipersonales, y ii) el mantenimiento en el artículo 87.2 LJCA del recurso de súplica, que la Ley 13/2009, de 3 de noviembre, había sustituido ya por el de reposición; cuestiones ambas ciertamente de tono menor, junto a las que no faltan otras de mucho mayor porte, como el olvido del retoque de los artículos 74.5 y 6 de la Ley orgánica del poder judicial y 10.5 y 6 LJCA, que siguen aludiendo a los suprimidos recurso de casación para unificación de doctrina y en interés de la Ley entre los asuntos de la competencia de las Salas de los Tribunales Superiores de Justicia, y la introducción, sin mínima y adecuada regulación, del recurso de casación por infracción de normas emanadas de las Comunidades Autónomas, ante una Sección especial de aquellas Salas de los correspondientes Tribunales Superiores de Justicia ${ }^{3}$.

En todo caso, cualquier reflexión de conjunto sobre la nueva casación debe efectuarse utilizando como criterios de referencia y, por tanto, valoración las finalidades perseguidas confesadamente por el legislador de la reforma y los medios por el empleado para alcanzarlos. Conforme al preámbulo de la Ley orgánica 7/2015, de 21 de julio ${ }^{4}$, cuya disposición final $3^{\mathrm{a}}$, más que refaccionar, renueva la sección $3^{\mathrm{a}}$ del capítulo $3^{\circ}$ del título IV LJCA, tales finalidades son las dos siguientes:

VIDA FERNÁNDEZ, J. (coords.), Los retos del Estado y la Administración en el siglo XXI: libro homenaje al profesor Tomás de la Quadra-Salcedo Fernández del Castillo, vol. 1, Ed. Tirant lo Blanch 2017. legislativa

Quintana Carretero, J.R. (2017) habla, a propósito de esta introducción, de defectuosa técnica

4 Dos son los párrafos del apartado XII del preámbulo aquí pertinentes. Su tenor literal es el siguiente:

"En este ámbito, y con la finalidad de intensificar las garantías en la protección de los derechos de los ciudadanos, la ley opta por reforzar el recurso de casación como instrumento por excelencia para asegurar la uniformidad en la aplicación judicial del derecho. De esta forma, el recurso de casación podrá ser admitido a trámite cuando, invocada una concreta infracción del ordenamiento jurídico, tanto procesal como sustantiva, o de la jurisprudencia, la Sala de lo Contencioso-administrativo del Tribunal Supremo estime que el recurso presenta interés casacional objetivo para la formación de jurisprudencia.

Con la finalidad de que la casación no se convierta en una tercera instancia, sino que cumpla estrictamente su función nomofiláctica, se diseña un mecanismo de admisión de los recursos basado en la descripción de los supuestos en los que un asunto podrá acceder al Tribunal Supremo por concurrir un interés 
a) La intensificación de las garantías en la protección de los derechos de los ciudadanos, para lo que se declara i) la opción por el reforzamiento del recurso de casación; ii) como instrumento por excelencia para asegurar la uniformidad en la aplicación judicial del Derecho, y iii) de forma que el recurso podrá ser admitido a trámite cuando, invocada una concreta infracción del ordenamiento jurídico, tanto procesal como sustantiva, o de la jurisprudencia, la Sala de lo Contencioso-administrativo del Tribunal Supremo estime que el recurso presenta interés casacional objetivo para la formación de jurisprudencia.

b) La evitación de la conversión de la casación en una tercera instancia, de modo que cumpla estrictamente su función nomofiláctica; a cuyo servicio se coloca el trámite de admisión [basado éste en i) la descripción de los supuestos que hacen recurrible un asunto por concurrir un interés casacional objetivo, a la que se anuda la diferenciación de aquéllos en que tal interés puede apreciarse respecto de los que llevan aparejada la presunción de la existencia de tal interés].

\section{SOBRE EL REFORZAMIENTO DEL REGURSO DE GASACIÓN Y LA INTENSIFICACIÓN DE LA PROTEGCIÓN DE LOS GIU- DADANOS}

\section{Consideraciones generales}

La valoración de la idoneidad de la reforma para alcanzar su primera y fundamental finalidad no puede dejar de partir del hecho de que la introducción de la casación en el orden jurisdiccional contencioso-administrativo ha ido acompañada del abandono de la universalidad de la apelación, es decir, de la construcción del control prescrito por el artículo 106.1 CE sobre el principio de la doble instancia (servida, al menos una de ellas, por un órgano judicial colegiado).

Dejando de lado la materia penal, es clara desde luego la inexistencia de una prescripción, sea por la Constitución, sea incluso por el Derecho internacional, de la doble instancia, pero ello nada dice acerca de la pertinencia de la construcción sobre tal principio -en ejercicio de la libertad de configuración de que goza el legislador en el marco constitucional- del funcionamiento del orden jurisdiccional contencioso-administrativo en atención a la peculiaridad de su función constitucional: el control del ejercicio conforme a Derecho del poder público administrativo.

casacional. Así, la Sala de casación podrá apreciar que en determinados casos existe interés casacional objetivo, motivándolo expresamente en el auto de admisión. El recurso deberá ser admitido en determinados supuestos, en los que existe la presunción de que existe interés casacional objetivo". 
En este sentido, a las razones que pueden aducirse a favor de supuestos de única instancia (reconducibles a la descarga de trabajo a los órganos judiciales y al más pronto otorgamiento de la tutela judicial) solo puede reconocerse - en la pertinente ponderación y por inscribirse en la lógica organizativa interna de la administración de la justicia- un peso inferior al que merecen:

a) De un lado, el principio del control de la actuación del poder público administrativo, que forma parte del sistema constitucional de controles de los poderes constituidos y cuya trascendencia, de difícil sobrevaloración, deriva del desplazamiento del centro de gravedad en el equilibrio entre las funciones estatales -como consecuencia de las transformaciones experimentadas por el Estado constituido- hacia el poder-función ejecutivo, con la consecuencia de la necesidad, cada vez más imperiosa, de la complementación del esquema monista clásico de la legitimación democrática orgánico-personal (reconducción de todo poder público al pueblo por intermedio del parlamento representativo, dotado de una posición preeminente), que deja en la sombra todo el complejo y amplio campo de la ejecución de la Ley en el que se confrontan, sin soluciones seguras (como es claro, por ejemplo, en el caso de las Administraciones independientes), las dos fuentes de legitimación: pueblo-representación y ciudadano-participación y demanda la ampliación del horizonte a la legitimación institucional-funcional-procedimental, en la que - portando la tarea a cumplir su propia legitimación- no hay lugar para el conflicto entre dichas fuentes de legitimación al pasar a ser clave la eficacia por bastar al ejercicio legítimo del poder - gracias al reconocimiento de grados o niveles de legitimación- una suficiente reconducción democrática. Lo que, al mismo tiempo, pone de relieve la singularidad del control judicial de la actuación administrativa respecto de la forma ordinaria de prestación de la tutela judicial efectiva.

b) La exigencia radical, por tanto, de la satisfacción del derecho fundamental a la tutela judicial en función de las características en que ésta ha de ser otorgada por razón de su objeto, que en este caso incluyen la de quedar implicada en el sistema de equilibrio entre poderes públicos. Desde este punto de vista, en efecto, ya antes de la reforma resultaba cuestionable, al menos en el caso de implicación -por escasa densidad de la programación normativa- de la entrega a la Administración de la definición del interés general o público, la exclusión de la doble instancia (con imposibilidad del acceso a la casación) en asuntos considerados de "menor entidad" solo por razón, en lo esencial, de su inscripción en los asuntos gestionados por la instancia territorial basal del Estado, es decir, la Administración local. Y ello, porque carácter "local" de un asunto en modo alguno equivale, sin 
más, a "poca o menor entidad", pues en la instancia local se ventilan y deciden cuestiones de indudable complejidad y trascendencia para la vida colectiva y los derechos de los ciudadanos en cuanto vecinos. Dicho de otra forma: a efectos del control no está justificada sin más la "gradación" de la "importancia" del interés público en función de la que resulta, para su progresiva "generalidad", de la articulación de la organización del Estado en comunidades o colectividades territoriales de amplitud cada vez mayor. Aparte de que, en todo caso, los términos en que han de adoptarse hoy las decisiones administrativas parecen requerir un doble examen en la judicial (sin perjuicio de que la tempestividad de la tutela judicial pudiera justificar un régimen más expedito de la ejecución provisional de la resolución judicial recaída en primera instancia), sobre todo bajo la forma de posibilidad de reconsideración por un órgano judicial colegiado de la decisión que adoptada por un órgano judicial unipersonal.

La descompensación que en la adecuada economía interna del sistema de impugnación de resoluciones judiciales suponía el recurso de casación en la versión vigente hasta la reforma comentada se ha visto notablemente agravada por el que dibuja esta reforma en la medida en que la intervención del mecanismo casacional pasa a ser selectiva precisamente en función del criterio del "interés", lo que no puede dejar de tener repercusión en el corpus de la jurisprudencia.

La evolución del recurso de casación mismo, que no puede desde luego desligarse del proceso de "normalización" del recurso contencioso-administrativo por el rasero del proceso civil, se ha desarrollado siempre en sentido restrictivo: desde la rigidificación de las condiciones de acceso, pasando por la exclusión de la invocación de Derecho autonómico y local y la restricción añadida por la jurisprudencia -sobre todo a partir del giro de ésta cumplido en los años 2010 y 2011- vía tanto la división artificial de la cuantía de los recursos para su colocación por debajo del umbral casacional, la conversión fáctica del escrito de preparación en un avance del de interposición o el reproche de ausencia o insuficiencia del juicio de relevancia exigido por el artículo 86.4 de la versión derogada de la LJCA, hasta la elevación legal del umbral del acceso a los 600.000 euros -equivalente al cegamiento de la casación para la práctica totalidad de los asuntos-. La reforma de 2015, sin embargo, lejos de situarse en línea de continuación de tal evolución, representa un verdadero salto cualitativo en tanto que, a pesar de la persistencia de su denominación, el recurso deja de ser, en último término, verdaderamente tal (convirtiéndose, en lo fundamental, de demanda en Derecho en simple petición de conocimiento de un asunto), es decir, muta en un mecanismo en la práctica plena disposición del Tribunal Supremo (incorporación 
de la lógica del certiorari, ajeno a nuestra cultura jurídica ${ }^{5}$ ) para hacerse con el conocimiento (restringido) del correspondiente asunto con finalidad casacional ${ }^{6}$, cuya actuación - eso sí- depende de iniciativa de legitimado para ello. Como ha dicho ya J. A. Santamaría Pastor ${ }^{7}$ :

"Se trata de la atribución a la Sala Tercera de un poder de selección de los asuntos a resolver empleando el exclusivo criterio del «interés casacional objetivo para la formación de jurisprudencia» (art. 88.1) que ofrezcan las cuestiones debatidas en el recurso. Este requisito opera conjuntamente con el de la presunta concurrencia de «una concreta infracción del ordenamiento jurídico, tanto procesal como sustantiva, o de la jurisprudencia»"8 (la negrita es mía).

En términos de su carácter, aunque sea apreciable un cierto paralelismo de su evolución con la de la casación francesa, el recurso, de instrumento nomofiláctico, se ha convertido en uno de unificación de la doctrina jurisprudencial, es decir, no tanto para decir lo que prescribe la norma (para proteger su mandato), cuanto para establecer y asegurar la interpretación judicial de la misma o, dicho de otro modo, para proteger lo que dice la jurisprudencia que dispone la norma9 ${ }^{9}$. Más que nomofiláctico, el recurso de casación actual se ofrece, pues, como nomotético. Cambio éste que, si asociado a la aclimatación que se hace de la función del Tribunal Supremo norteamericano (en todo caso parcial e incompleta, en la medida en que no aparece completada con el mecanismo complementario del stare decisis; aunque este efecto puede considerarse que está implícito), no fue precisamente bien recibido por parte

\footnotetext{
Y ni siquiera fielmente. Pues la introducción del certiorari en los EEUU a finales del S. XIX se acompañó de la creación de los Circuit Courts of Appeal responsables del conocimiento de las apelaciones hasta entonces atribuidas al Tribunal Supremo. En nuestro caso, el nuevo recurso de casación se implanta prescindiendo del dato de la no universalidad del recurso de apelación.

Sobre esta inspiración ya antes SANTAMARÍA PASTOR, J. A. (2015) y PÉREZ ALONSO, J. (2015).

No cabe olvidar tampoco que la transformación del recurso de casación parece seguir la estela de la reforma por la Ley orgánica 6/2007, del recurso de amparo, introduciendo en el artículo 50 de la Ley reguladora del Tribunal Constitucional un trámite de admisión en el que el criterio decisivo es la "especial trascendencia constitucional" del recurso.

6 Como señala RUIZ LÓPEZ, M. A. (2017: 169), el concepto jurídico indeterminado “interés casacional objetivo" intensifica "... la defensa del ius constitutionis frente a la garantía del ius litigatoris".

7 SANTAMARÍA PASTOR, J. A. (2015: 21 in fine y 22).

$8 \quad$ Infracción, debe añadirse, que es solo el presupuesto, no el objeto del recurso, al igual que el acto-actuación de la Administración es presupuesto y no el objeto -integrado por las pretensiones deducidas por las partes- del recurso contencioso-administrativo.

$9 \quad$ A este respecto, RUIZ LÓPEZ, M. A. (2017: 169), apunta que lo primordial ahora en la casación no es la tutela de derechos o intereses legítimos, sino convertir la casación en instrumento al servicio de la "formación de jurisprudencia" desde el entendimiento de que la selección discrecional de los asuntos ha de redundar en la eficiencia de la jurisdicción.
} 


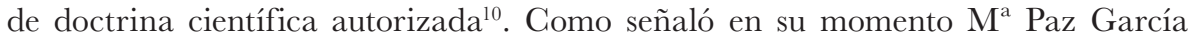
Rubio (a propósito de la evolución del recurso casación civil; opinión trasladable a nuestro examen por razón de la ya expresada "normalización" del recurso contencioso-administrativo en función del modelo del proceso civil $)^{11}$ :

"Lo que no cabe duda es que la nueva regulación del recurso de casación pretende reforzar el papel del Tribunal Supremo como órgano destinado a lograr una aplicación unificada del Derecho civil, lo que se plasma en el nuevo concepto de "interés casacional". Este interés casacional se manifiesta de dos modos distintos: por una parte, como fórmula para solucionar la vulneración de la jurisprudencia del Tribunal Supremo, lo que supone sin duda cierta vinculación al precedente por parte de los órganos inferiores, los cuales verán revocada su resolución cuando se aparten de él; por otra, como instrumento válido para crear jurisprudencia (que a su vez provocará la posterior vinculación de los órganos jurisdiccionales inferiores), tanto superando la existencia de pronunciamientos contradictorios de las Audiencias Provinciales, como en el caso de que por su escaso periodo de vigencia, se trate de normas sobre las que no existe jurisprudencia.

A nuestro entender esta nueva habilitación legal a través de concepto de "interés casacional" para crear jurisprudencia cuya violación va a ser, a su vez, causa de un nuevo "interés casacional", supone un decidido paso adelante en el reconocimiento del papel de los Tribunales en la fijación de las normas, lo que no es sino un eslabón más en el reconocimiento legal de la creación judicial de Derecho" (la negrita es mía).

\section{Balance posible de la reforma}

Se está ya así en condiciones de efectuar, en el marco de lo dicho, un primer balance de la reforma en términos de identificación de sus ventajas o aspectos susceptibles de ser valorados positivamente, de un lado, y sus desventajas o extremos merecedores de ser valorados negativamente, de otro.

10 Véase el debate suscitado ya en 2002 por la iniciativa de reforma de la casación (artículos de los Profs. GARCíA DE ENTERRÍA, E., DÍEZ-PICAZO, L. y MUÑOZ MACHADO, S. así como del entonces Presidente del Tribunal Supremo y del Consejo General del Poder Judicial, HERNANDO SANTIAGO, D. J. publicados en el periódico ABC) y recogidos en el Foro Iustel (accesible en internet: www. iustel.com).

11 GARGía RUBIO, M. P. "Jurisprudencia, Constitución, Ley de Enjuiciamiento Civil", texto recogido en el Foro Iustel citado en nota anterior. 
Entre los aspectos o extremos que ameritan un juicio positivo (en su caso, con matizaciones), cabe destacar los siguientes:

$1^{\circ}$. La ampliación de las resoluciones susceptibles de examen casacional, toda vez que -dejando al margen la permanencia lógica de las excepciones comprensivas de los asuntos relativos al ejercicio del derecho fundamental de reunión y los procesos electorales- se suprimen las exclusiones que afectaban a las resoluciones de los órganos judiciales unipersonales y las de los órganos colegiados dictadas en apelación. En efecto, son ahora "recurribles" (arts. 86.1 y 87 LJCA):

- Las Sentencias de los Juzgados de lo Contencioso-Administrativo dictadas en única instancia.

- Determinados Autos y las Sentencias (dictadas en única instancia o en apelación) de las Salas de los Tribunales Superiores de Justicia y de la Audiencia Nacional.

En el caso de los Autos, sin embargo, importa precisar que:

i) No queda clara la completa irrecurribilidad de los dictados por todos los Juzgados de lo Contencioso-Administrativo. Pues podría entenderse que sí lo son indirectamente (a través de los Autos que dicten) cuando las Salas de los Tribunales Superiores de Justicia o de la Audiencia Nacional resuelvan precisamente por Auto la apelación de que sean objeto, si bien tal solución no se impone como evidente y habrá que esperar al criterio que acabe sentando el Tribunal Supremo. Como también cabría pareja solución en el caso de que la impugnación se resuelva mediante Sentencia de los correspondientes órganos colegiados superiores, si bien aparece dificultada por la limitación literal en el artículo 86.1 LJCA de la recurribilidad de las Sentencias dictadas en apelación a las dictadas precisamente contra Sentencias, a su vez, de los Juzgados. De modo que en este punto es más indicada aún la espera al criterio que siente el Tribunal Supremo.

ii) Los dictados en aplicación de los artículos 110 LJCA [previsor de la extensión de los efectos de las Sentencias en las materias tributaria, de personal de las Administraciones públicas y unidad de mercado] y 111 LJCA [posibilidad de la extensión de los efectos de las Sentencias recaídas en procesos que se hayan tramitado con suspensión de la de otros asuntos acumulables al mismo] han dejado de ser recurribles "en todo caso", equiparándose su condición de procedencia al resto de los supuestos. 
$2^{\circ}$. La reducción a una (si bien con dos variantes: la estatal y la autonómica) de las modalidades de casación existentes (la común, la de unificación doctrina y la en interés de la Ley, más - en el caso de las dos últimas- de las variantes estatal y autonómica). Reducción ésta absolutamente pertinente teniendo en cuenta la más que reducida utilidad -por razón del criterio restrictivo manejado en su aplicación por el Tribunal Supremo- de los recursos para unificación de la doctrina jurisprudencial y en interés de la Ley.

$3^{\circ}$. La supresión de los motivos específicos de ilegalidad invocables. Y ello -tal como ya ha argumentado J. A. Santamaría ${ }^{12}$ - no solo porque todos los que estaban previstos no eran sino innecesarias especificaciones del consistente en la infracción del ordenamiento o de la jurisprudencia, sino porque elimina la incertidumbre sobre el acierto en la selección del motivo en cada caso invocado.

$4^{\text {}}$. La clarificación del régimen de impugnación de los Autos por la nueva redacción del inciso inicial del artículo 87.1 LJCA, pues queda precisada i) la exclusión de los Autos recaídos en procesos de protección del ejercicio del derecho de reunión y materia electoral; y ii) la exigibilidad en los correspondientes recursos del juicio de relevancia y carácter determinante del Derecho estatal y de la Unión Europea prescrito por el artículo 86.3 LJCA (sin perjuicio de la crítica que sin duda merece tal exigibilidad por su carácter solo formal o ritual, en tanto que los motivos esgrimibles en estos recursos conforme al artículo 87.1 LJCA se reducen prácticamente a infracciones de la LJCA).

Juicio netamente negativo (en diverso grado) ameritan, por el contrario, las siguientes previsiones:

a) El innecesario problema interpretativo, ya mencionado, generado por la alusión genérica a los Juzgados de lo Contencioso-Administrativo en el artículo 86.1 LJCA. Esta alusión, indudablemente inercial (recuérdese la rectificación realizada a este respecto por la Ley 37/2011), obliga a entender (porque toda otra solución conduciría a un absurdo) que su empleo en este caso tiene manifiestamente vocación de cubrir tanto los órganos unipersonales provinciales, como los centrales.

b) La introducción por la redacción literal del artículo 87.1 LJCA, dada su referencia solo a los Autos de los órganos colegiados, de la incertidumbre ya comentada y en la que no es necesario así insistir ahora.

12 SANTAMARÍA PASTOR, J. A. (2015: 22). 
c) La limitación de la "recurribilidad" de las Sentencias de los órganos unipersonales a las que contengan doctrina que se repute gravemente dañosa para los intereses generales y susceptibles de extensión de sus efectos.

No se descubre ahora nada nuevo al señalar el carácter ciertamente discutible del supuesto, en la medida en que, de un lado, coincide, al menos en parte sustancial, con uno de los indiciarios de la presencia de interés casacional objetivo -concretamente el del artículo 88.2, b) LJCA- y, de otro lado, guarda, también en parte, gran parecido con otro de ellos: el del artículo 88.2, c) LJCA.

La coincidencia puede llevar razonablemente ${ }^{13}$ a la conclusión de que, en este caso, el recurso es legalmente inadmisible por cualquiera de los otros supuestos indiciarios de interés casacional. Habrá que esperar en este punto a la interpretación que haga el Tribunal Supremo.

La semejanza es, por el contrario, más aparente que real. Pues la alusión a la susceptibilidad de extensión de los efectos hace referencia claramente al supuesto del artículo 110 LJCA (Sentencias recaídas en materia tributaria, de personal al servicio de las Administraciones y unidad de mercado), así como, en su caso, también al del artículo 111 LJCA.

Sea como fuere, el juego combinado de los dos requisitos ahora examinados permite sumarse al augurio de un futuro no precisamente positivo para la impugnación en sede casacional de las Sentencias de los órganos unipersonales en única instancia en atención al criterio francamente restrictivo mantenido hasta ahora por el Tribunal Supremo para la apreciación de grave daño a los intereses generales en sede del recurso de casación en interés de la Ley. Cara a dicho futuro no cabe sino confiar en un cambio de criterio (en sentido ampliatorio) por el Tribunal Supremo.

d) El mantenimiento de la restricción, para las Sentencias dictadas por los órganos colegiados, de la involucración de Derecho estatal o de la Unión Europeo (por haber sido invocado o considerado) de modo relevante y determinante para el fallo. Pues determina el carácter incompleto de la función del Tribunal Supremo (generación y aseguramiento de la jurisprudencia en un sistema, como el nuestro, de unidad del Estado (y, por tanto, de su ordenamiento jurídico) y unicidad del poder judicial (teniendo en cuenta que la legitimación del control judicial no procede del bloque principial democracia-pluralismo político, sino del conjunto de los que se subsumen en el Estado de Derecho. 
e) La innecesariedad de la calificación (art. 88.1 LJCA) como objetivo del interés casacional, pues si lo que pretende indicar es la dependencia de su efectiva concurrencia solo de una libre decisión (el certiorari implica un volemus), tal significado ya está de suyo implícito en la configuración misma de la nueva casación.

El interés casacional se acota, en efecto, mediante una doble relación indicativa, es decir, no exhaustiva de supuestos, que más que dotar a la casación contencioso-administrativa una amplitud mucho mayor que la prevista para la civil hace innecesariamente más complejo en aquélla el requisito de la "recurribilidad". Y, si bien la relación se desglosa en dos para que la aplicación de una de ellas quede entregada sin más al Tribunal Supremo, mientras la de la otra se condiciona mediante una presunción legal, lo cierto es que el alcance de tal desglose es relativo, pues en una como en otra la apreciación de la concurrencia es siempre libre para la Sala. Lo que hay es, pues, una gradación de la discrecionalidad decisional de ésta: la presunción solo la limita por relación a la exigencia de motivación.

f) A todo lo anterior puede añadirse, de un lado, el olvido en el artículo 88 LJCA de algún supuesto importante apuntado por alguna doctrina ${ }^{14}$ (así, el de inaplicación de una Ley por infracción de Derecho de la Unión Europea), y, de otro lado y en el otro extremo, la inclusión de otros en los que resulta difícil encontrar indicio de interés casacional: es el caso de los convenios interadministrativos, los acuerdos de organismos reguladores ${ }^{15}$ y los actos de los Gobiernos o Consejos de Gobierno de las Comunidades Autónomas [teniendo en cuenta, en este último caso, que la inclusión en él de las disposiciones de dichos Gobiernos o Consejos de Gobiernos es redundante, pues el supuesto ya está comprendido de suyo en el más amplio de la letra g) del apdo. 2 del artículo 88 LJCA].

g) Y, lo más grave de todo: la previsión de una "casación autonómica" ante una Sección específica de las Salas de lo Contencioso-Administrativo de los Tribunales Superiores de Justicia por infracción de normas emanadas de las correspondientes Comunidades Autónomas (art. 86.3, párrfs. $2^{\circ}$ y $3^{\circ}$ LJCA) precisando solo (y aún así de modo muy deficiente, si se consideran las dificultades para formar la aludida Sección en Tribunales Superiores

14 SANTAMARÍA PASTOR, J. A. (2015: 24).

15 Amén de la crítica que merece, como ya ha sido señalado en la doctrina, la mención de las agencias estatales que, sobre estar hoy suprimidas, se inscriben en el campo de la competencia no de la Audiencia Nacional sino de los Juzgados Centrales de lo Contencioso-Administrativo (debiendo tenerse en cuenta que la Agencia Española de Protección de Datos, comprendida en la disposición adicional $4^{\text {a }}$ LJCA no es propiamente una agencia estatal, siendo como es una Administración Independiente). 
de Justicia en los que la Sala de lo Contencioso-Administrativo tenga un número insuficiente de Magistrados) el órgano judicial llamado a conocer, determinando inacabadamente el objeto del recurso y omitiendo toda regulación de los esenciales aspectos del mismo: además del objeto mismo, las resoluciones recurribles, los requisitos y el procedimiento. Se entiende, así, que, dadas estas circunstancias, en sede del Tribunal Superior de Justicia de Valencia se llegara a dictar un Auto de inadmisión por inexistencia del recurso (Auto que fue corregido inmediatamente por otro, de 13 de marzo de 2017, de la Sección de Casación, fijando doctrina al respecto) o en la del Tribunal Superior de Cataluña otro Auto, de $1^{\circ}$ de mayo de 2017, negando la recurribilidad de las Sentencias de la propia Sala y se esté funcionando sobre la base de los criterios, no enteramente coincidentes, sentados justamente por las Secciones de Casación de los correspondientes Tribunales. Una situación de todo punto de vista insatisfactoria, teniendo en cuenta que se añade a las características ya expuestas del nuevo recurso y que se sitúa en la frontera misma de lo admisible en sede judicial en tanto que rayana -bajo el insuficiente disfraz de una aplicación analógica, de suyo cuestionable, de la regulación del recurso de casación ante el Tribunal Supremo- en la asunción de una función completiva de la Ley (limitado constitucionalmente a juzgar y ejecutar lo juzgado, con prohibición- art. 117.4 del texto constitucionalde toda otra función ajena a las atribuidas por la Ley en garantía de los derechos).

La previsión de esta variedad del recurso de casación trae causa desde luego de la restricción del Tribunal Supremo al conocimiento de la infracción del Derecho estatal, pero en modo alguno resulta obligada por la previsión del artículo 152.1 de la Constitución, en la medida en que éste se limita a establecer la culminación por un Tribunal Superior de Justicia de la organización judicial en el ámbito territorial de la Comunidad Autónoma correspondiente, sin perjuicio (que es lo esencial) de la jurisdicción que corresponde al Tribunal Supremo. Pues en tanto que partes ambos del único poder judicial constituido, dicho Tribunal Superior, capaz de conocer en sede casacional de la infracción autonómica, en nada se diferencia - a estos efectos- del propio Tribunal Supremo. La solución es, pues, estrictamente legal y, en tal plano, muy discutible a la vista de la reserva de Ley orgánica resultante del artículo 122.1 de la Constitución y la propia Ley orgánica del poder judicial (que no solo nada dice sobre el nuevo recurso autonómico, sino que continua aludiendo a los viejos recursos de casación). La aplicación analógica al autonómico de la regulación que la LJCA hace del recurso de casación ante el Tribunal Supremo, que parece estar en la base de los criterios hasta ahora sentados en sede judicial, sobre ir más allá 
de lo permitido en una operación de integración de una laguna legal, es de todo punto, no ya insuficiente para resolver alguna grave cuestión que suscita la convivencia de los recursos autonómico y general (como el de la compatibilidad o no entre ellos y, en su caso, la preferencia de uno sobre el otro por razón de la aplicación en un mismo asunto, conjuntamente, de Derecho estatal y autonómico), sino inadecuada (aunque expresiva del papel creciente que viene asumiendo la jurisprudencia) para establecer, conforme exige el principio de Estado de Derecho, el régimen de un recurso, siquiera sea uno de las características tan peculiares como el de casación. Por tanto, es necesaria y urgente la intervención del legislador para subsanar las deficiencias que dicho régimen padece.

\section{CONCLUSIONES. LA VERDADERA NOVEDAD DE LA AGTUAL CASAGIÓN}

El precedente balance autoriza a afirmar que:

$1^{\circ}$. El actual recurso de casación no es estrictamente nomofiláctico, pues en él la nomofilaxis (entendida como protección directa de la norma) aparece clara y totalmente intermediada por la jurisprudencia. Lo que hace que el recurso merezca mas propiamente la calificación de nomotético.

Avalan tal calificación la finalidad específica implícita en: i) los supuestos en que es posible la apreciación de interés casacional objetivo: el establecimiento de jurisprudencia, es decir, la interpretación de las normas; el control de la solución a dar a las cuestiones de inconstitucionalidad; el control de la efectividad de la doctrina constitucional y de la jurisprudencia del Tribunal de Justicia de la Unión Europea; y el control de la tutela judicial ordinaria reforzada de los derechos fundamentales; y ii) los supuestos en que opera la presunción de concurrencia de interés casacional objetivo: la fijación de jurisprudencia (en caso ausencia de la misma respecto de las normas aplicadas); y el control de la observancia de la jurisprudencia ya establecida.

Argumento definitivo en este orden de consideraciones lo proporcionan los supuestos de procedencia de la inadmisión del recurso (art. 90.4 LJCA), en los que se incluye, aparte los relativos o relacionados con los requisitos de preparación, el de "carencia en el recurso de interés casacional objetivo para la formación de jurisprudencia".

La casación se aparta, así, de lo nomofiláctico para convertirse en mecanismo depurador del control judicial cumplido en asuntos en los que esté afectado gran número de situaciones, tengan trascendencia social o esté en juego la integridad de los intereses generales (por lo que hace a los supuestos en que es simplemente posible la apreciación de su interés casacional), así como - de manera más sorprendente- en aquéllos en que estén implicados relaciones interadministrativas, la función de re- 
gulación atribuida a Administraciones independientes o decisiones de los Gobiernos o Consejos de Gobierno de las Comunidades Autónomas (por lo que respecta a los supuestos en que legalmente se presume la concurrencia de interés casacional). Lo sorprendente en estas últimas hipótesis es la diferente perspectiva en que descansan y que suscita la sospecha de que en ellas subyace un propósito de hacer posible el control último por el Tribunal Supremo del funcionamiento coherente del poder público administrativo en sus espacios de máxima descentralización territorial y funcional y, por ello, la puesta del interés casacional - entendido como referido a los intereses de la instancia general del Estado- al servicio de la articulación de dicho poder público.

El único resto del carácter propiamente nomofiláctico radica en el supuesto de nulidad de las disposiciones de carácter general. Pero este resto subsiste solo relativa y limitadamente, ya que en dicho supuesto ya no procede el recurso "en todo caso", sino solo si hay justamente apreciación de interés casacional.

Sin perjuicio de que la nueva casación no consiga tampoco ahora asegurar la uniformidad de la jurisprudencia, pues: a) no cubre el Derecho autonómico, ni el local; b) opera de modo aleatorio y c) no cuenta con el apoyo de la expresa imposición a los Juzgados y Tribunales del deber de estar a la jurisprudencia, otorga en cualquier caso a ésta un papel relevante, superior o más potente que el de mero complemento del ordenamiento que cumple, conforme con el artículo 1.6 del Código Civil, conjuntamente con la costumbre y los principios generales del Derecho.

$2^{\circ}$. Aunque continúe calificándose de recurso (extraordinario), lo cierto es que no le cuadra ya estrictamente tal cualidad. Pues para que pueda predicarse ésta es precisa la determinación reglada (por más restrictiva que sea) del acceso, es decir, del requisito de la "recurribilidad", pues solo en tal caso puede existir un derecho al recurso. Y tal derecho ha dejado de existir propiamente en el régimen legal examinado, puesto que solo regla los requisitos de cumplimiento obligado cuya satisfacción es presupuesto de la mera posibilidad de la apreciación del interés casacional y, por tanto, de la admisión. Es concluyente el dato de que, aunque entre aquellos requisitos siga figurando la legitimación para recurrir, la inclusión de ésta en la minuciosa lista de los formales a cumplir contrasta vivamente con la ausencia de toda previsión legal sobre quienes están legitimados (la Ley orgánica 7/2015 simplemente ha olvidado reproducir el antiguo artículo 89.3 LJCA, que era el que precisaba quiénes ostentaban legitimación). Por tanto, la legitimación continúa operando como un requisito al estar aludida en la letra a) del apdo. 2 del artículo 89 LJCA, pero su cumplimiento no proporciona ex lege (por ausencia de predeterminación en ella) derecho a cuestionar la correspondiente resolución judicial en sede casacional. De este modo, el requisito de "recurribilidad" es formal y, todo lo más, un eufemismo que oculta la inexistencia de derecho al recurso. 
En efecto:

- En los supuestos del artículo 88.2 LJCA la apreciación de interés casacional objetivo es una facultad totalmente discrecional del Tribunal Supremo, en cuyo ejercicio éste goza -dados los términos abstractos y abiertos en ellos utilizados ("cuestiones sustancialmente iguales", "gravemente dañosa" [una resolución], "gran número de situaciones", "suficientemente esclarecida" (la de plantear una cuestión de inconstitucionalidad); y "contradicción aparente")- de un muy amplio margen de maniobra. Así lo prueba el dato de que la inadmisión se produzca, como regla general [artículo 90.3, a) LJCA], por Providencia que no es preciso legalmente que tenga verdadera motivación y, solo como excepción, por Auto - éste si motivado- cuando Sala de instancia haya emitido opinión favorable sobre el interés casacional; pero a cambio la admisión - y esto es significativo- requiere en tal caso Auto motivado.

- En los supuestos en que juega la presunción legal del interés casacional la admisión sigue siendo, a pesar de las apariencias, igualmente una facultad discrecional. Aunque según el artículo 90.3, b) LJCA rige aquí, para la inadmisión, la regla inversa: Auto motivado, ella misma acredita que la presunción legal es solo iuris tantum, de modo que su destrucción solo requiere un plus de motivación.

- Y ha de tenerse en cuenta, finalmente, que contra las Providencias y Autos de inadmisión y admisión no cabe ulterior recurso (art. 90.5 LJCA).

El nuevo régimen de la casación suscita así la cuestión, en definitiva y con especial intensidad, del papel del Tribunal Supremo como órgano en el que culmina la organización del poder judicial. Mas concretamente: la de si dicho papel ha de definirse a partir de un planteamiento centrado en la organización de un servicio público (por más que peculiar) o más bien de uno que descanse en la implicación del ejercicio de un poder público constituido clave (el más determinante por poseer la última palabra en los asuntos controvertidos) para la efectividad del Estado de Derecho.

La reforma analizada no es consecuencia de un análisis de los requerimientos del marco constitucional y, concretamente, de la división y el equilibrio entre poderes implicado en el control asignado al orden jurisdiccional contencioso-administrativo). Antes bien está hecha a todas luces desde el punto de vista hoy tan en boga del funcionamiento del poder judicial en el otorgamiento de la tutela judicial, por lo que se ofrece guiada por la idea de que se está ante la prestación de un servicio a los ciudadanos que, para que tenga calidad, es preciso que su funcionamiento sea fluido, es 
decir, cumpla su misión de modo tempestivo y eficaz. Pero ésta es más bien una cuestión organizativa interna: la de la idoneidad de la Administración de Justicia para cumplir su tarea, en modo alguno la cuestión decisiva de que verdaderamente debería tratarse: la relativa al control del poder público administrativo en conexión con la tutela judicial garantizada; tutela, que -en cuanto derecho fundamental y uno de los pocos derechos que, por instrumental y formal, debería poder ser garantizado en su efectividad por el Derecho- no puede experimentar modulaciones o restricciones (adaptando los requisitos de acceso al "servicio" a la demanda real) que - en tanto que pertenecientes al plano de los medios- pertenecen al plano de lo organizativo interno.

A modo de conclusión puede decirse que dada la "factura" del nuevo "recurso" de casación, habría sido preferible:

- La remodelación del sistema sobre la base de la doble instancia (la universalidad de la apelación), en su caso en los términos del sistema alemán (apelación universal, pero restringida).

- Y la articulación de la casación bien - en línea de continuación con el proceso de "normalización" de lo contencioso-administrativosobre la lógica mucho más simple y clara de la casación civil (o, en su caso, de la revisión civil alemana más simple y operativa (regulada en la legislación procesal civil: Zivilprozessordnung) ${ }^{16}$, bien prefiriendo al modelo norteamericano el alemán de la revisión en lo contenciosoadministrativo (regulada en la Verwaltungsgerichtsordnung) en cuanto presenta la ventaja de representar una (limitada) tercera instancia justamente federal.

16 Según los arts. 542, 545 y 546 de la Zivilprozessordnung, la revisión procede contra las Sentencias dictadas en apelación por descansar el fallo en una infracción del Derecho, la cual se produce siempre que una norma jurídica (en sentido material) no haya sido aplicada o lo haya sido incorrectamente. 